УДК 811.134.2'42

ББК 81.472.1-51

DOI: https://doi.org/10.17308/lic.2021.2/3417

\title{
МАНИПУЛЯТИВНЫЕ СТРАТЕГИИ В АНГЛОЯЗЫЧНОМ МЕДИАПРОСТРАНСТВЕ
}

\author{
А. Б. Недзельская, О. О. Борискина \\ Воронежский государственный университет \\ MANIPULATIVE STRATEGIES \\ ON ENGLISH-LANGUAGE MEDIA SCENE
}

\author{
A. B. Nedzelskaya, O. O. Boriskina \\ Voronezh State University
}

\begin{abstract}
Аннотация: в статье рассматривается манипулятивное воздействие как ведущая дискурсивная социальная практика, представляющая собой комплекс стратегических и тактических составляющих, направленный на формирование общественного мнения на всем медиапространстве. Информационной базой исследования послужили англоязычные статьи из электронных ресурсов британских и американских СМИ и публикации в социальных сетях. Механизмы языковой манипуляции рассматриваются с позиций «тактико-стратегического» подхода. Выделены и описаны базовые характеристики манипуляци. Манипулятивные стратегии по степени искажения информаџии условно разделены на стратегии фактологического манипулирования и стратегии идеологической поляризации. Достижение эффекта в обоих случаях происходит через реализаџию макростратегий легитимации и дискредитации. Особое внимание уделяется наиболее частотным тактикам стратегий дискредитации, а макростратегия легитимации рассматривается с позиции теории проксимизации. Проксимизация представляет собой манипулятивную стратегию обращения к событиям, отдаленным от текущего момента в пространственном, временном или аксиологическом плане, но способным символически перемещаться на первый план (усилиями актора), ближе к информационному иеентру, в котором находятся манипулятор и манипулируемый. Реализация всех уровней проксимизации способствует достижению манипулятивного эффекта - уверенности объекта манипулирования в необходимости немедленных мер по предотвращению рисков и позволяет легитимировать планируемые манипулятором действия.
\end{abstract}

Ключевые слова: медиапространство, манипулящия, манипулятивная стратегия, тактика, дискредитация, легитимация, проксимизация.

\begin{abstract}
: the article considers manipulative persuasion as the main discursive social practice consisting of strategies and tactics aimed to shape public opinion on the media scene. The research information base is Englishlanguage articles in e-resources of British and American media and posts in social networks. The mechanisms of linguistic manipulation are considered from the perspective of the tactics and strategic approach. The basic features of manipulation are distinguished and described. The manipulative strategies are conveniently classified into strategies of factual manipulation and strategies of ideological polarization according to the degree of misrepresentation of information. In both cases the effect is achieved by implementation of macrostrategies of discredit and legitimation. The specific focus is made on the most frequent tactics of discrediting strategies while macrostrategy of legitimation is considered from the perspective of proximisation theory. Proximisation is a manipulative strategy of addressing events distant from the present moment in space, time and moral plan but able to symbolically shift to the foreground (by an actor's efforts) closer to the information centre where a manipulator and a recipient are. Proximisation on all levels allows to achieve manipulative effect, namely belief in the need for immediate measures to prevent risks, which facilitates legitimating action planned by a manipulator. Key words: media, manipulation, macrostrategy of discredit, tactic, legitimation, proximisation.
\end{abstract}

(C) Недзельская А. Б., Борискина О. О., 2021

Контент доступен под лицензией Creative Commons Attribution 4.0 License.

The content is available under Creative Commons Attribution 4.0 License. 


\section{Введение}

В последние два десятилетия интерес к манипуляции как ведущей дискурсивной практике в лингвистических исследованиях заметно возрос, что объясняется неуклонно увеличивающейся ролью медиа в формировании внутриполитической повестки государств.

На фоне растущего по экспоненте интереса к манипулятивным технологиям наблюдается расширение спектра новых носителей информации и инструментов коммуникации, происходит модификация традиционных каналов общения, постоянно совершенствуется арсенал технологических решений, peализация которых приводит к появлению коммуникативного продукта - традиционного или все чаще мультимодального текста. Цифровая революция диктует необходимость изучения манипулятивных стратегий в тесной связи с поликодовостью, интертекстуальностью, цифровой средой «обитания» текстов, ведь Цифровое медиапространство - идеальная среда для реализации намерения влиять на общественное сознание, где особую роль играют социальные сети, выполняющие сегодня роль новых медиа. Они фактически переходят в статус регулятора общественным мнением, «у общественности происходит создание иллюзии добровольного принятия излагаемого мнения... осознание необходимости совершения определенных действий, ожидаемых манипулятором» $[1$, c. 58].

Актуальность заявленной проблематики обусловлена также и тем, что в условиях глобализации при доминирующей роли английского языка в медиапространстве изучение манипулятивных стратегий англоязычного дискурса (в первую очередь политического) приобретает особую значимость как для эффективного межкультурного взаимодействия, так и для выявления и устранения риска социального напряжения в поликультурном обществе.

В фокусе настоящего исследования - манипулятивное воздействие, являющее собой комплекс стратегических и тактических составляющих, направленный на формирование общественного мнения на всем медиапространстве. Манипулятивная стратегия - это долгосрочное магистральное направление усилий по представлению информации, подчиненное достижению максимального манипулятивного воздействия на адресата. Реализация стратегии предусматривает создание необходимых и достаточных условий, выбор оптимальных мультимодальных (включая языковые) средств манипулирования.

Любопытно, что успешность коммуникации, заточенной на манипулирование, предполагает внутреннюю эмоциональную готовность реципиента согласиться с адресантом, возникающую на фоне низкой информированности о предмете разговора, стереотипности мышления, наличия болезненных травм прошлого в обществе или социальной группе, к которой принадлежит реципиент.

Адекватное же коммуникативное поведение (распознавание манипулятивного призыва, его оценка, осознанная реакция неприятия медиаконтента) свидетельствует о коммуникативной неудаче в реализации манипулятивной стратегии.

\section{Материалы и методы исследования}

Теоретической базой настоящего исследования послужили труды отечественных и зарубежных ученых, исследующих природу манипулятивного воздействия (Е. Л. Доценко, С. А. Зелинский, С. Г. Кара-Мурза, И. А. Стернин, Е. С. Кубрякова, Г. Г. Почепцов, Г. А. Копнина, А. А. Бернацкая, И. В. Евсеева, А. В. Колмогорова, В. И. Карасик, П. Чилтон, Т. ван Дейк, Н. Хомский, Р. Водак, Н. Н. Фэйрклаф, Т. ван Леувен), условия его осуществления (Э. В. Будаев, А. П. Чудинов, О. Н. Быкова, Л. И. Гришаева, М. Р. Желтухина, П. Цап, А. П. Сковородников, О. О. Борискина, Л. В. Цурикова, А. В. Антонова), его разновидности (А. К. Михальская, Н. Н. Кошкарова, Т. А. Ширяева, О. А. Солопова, С. Л. Кушнерук, О. И. Исмаилова, К. В. Кучеренко, Д. С. Мухортов, О. А. Гаврикова, О. Н. Иванищева, О. С. Дейнека, С. Н. Ильченко, Л. В. Калинина, Ю. М. Ершов, К. В. Андрианова, Т. М. Голубева), стратегии и тактики (Е. И. Шейгал, О. С. Иссерс, О. Л. Михалева, А. А. Данилова, Г. А. Копнина, В. И. Озюменко, Ю. Р. Тагильцева, Н. Б. Руженцева, Н. С. Рядовая), языковые и мультимодальные средства и приемы манипуляции (С. Г. Агапова, А. М. Шестернина, Р. В. Жолудь, Л. Г. Навасартян, И. Г. Катенева, Ю. А. Горностаева, Т. В. Марченко, О. Г. Мельник, О. В. Обвинцева, А. А. Полякова, Р. В. Агаджанян).

Феномен манипуляции является объектом исследований в философии, психологии, социологии, политологии, экономике, юриспруденции, антропологии, менеджменте, маркетинге, журналистике, педагогике, семиотике и лингвистике. Построение манипуляционного высказывания изучают в рамках различных научных направлений (дискурс-анализа, когнитивной науки, лингвокультурологии, медиаведения). При этом все заметнее становится тенденция на междисциплинарность, которая позволяет описывать манипулятивные механизмы с разных сторон, «прогнозировать реакцию реципиента, основываясь на лексико-семантических, грамматических, фонетических и риторических законах языка» [2, с. 28].

Большой вклад в исследование манипулятивного воздействия медиадискурса внес лингвист и дискурс-аналитик Т. ван Дейк. В его работах впервые перенесен фокус с чисто социологического анализа манипуляции на рассмотрение лингвостилистических особенностей медиадискурса. 
В отечественной лингвистике двадцать первого века успешно разрабатывается «тактико-стратегический» подход, который позволяет «выявить и описать некоторые тенденции и закономерности в использовании языковых средств при манипуляции массовым реципиентом именно в терминах стратегии и тактики» [3, с. 12].

Информационной базой настоящего исследования послужили англоязычные статьи из электронных ресурсов британских и американских СМИ: ВВС, CNN, The Guardian, The Independent, The New York Times, The Washington Post, публикации в социальных сетях Twitter и Facebook.

В исходном значении термин «манипуляция» обозначает сложные виды действий, выполняемых руками. Переходной ступенью к метафорическому значению стало использование термина в случаях, когда эффект достигается за счет механизмов психологической установки, стереотипных представлений и иллюзий. Полный переход к метафоре приводит к смене объектов и средств и ведет к тому, что «под объектами действий-манипуляций понимаются уже не предметы, а люди, при этом сами действия выполняются уже не руками, а с помощью иных средств» [4, с. 48].

Традиционное понимание манипуляции как вида психологического воздействия, которое «ведет к скрытому возбуждению у другого человека намерений, не совпадающих с его существующими желаниями» [4, с. 52], расширилось после исследований T. ван Дейка, где манипуляция рассматривается как «дискурсивная социальная практика доминантных групп, направленная на воспроизводство их власти» [5, p. 364]. Такое широкое понимание манипуляции предполагает и множество подходов к исследованию данного явления: либо с целью изучения злоупотребления властью (социальный аспект), либо для изучения контроля над сознанием (когнитивный аспект), либо с лингвистических позиций дискурсивно-семиотического феномена.

В связи с этим в лингвистическое описание вводится понятие языковой манипуляции как разновидности «манипулятивного воздействия, осуществляемого путем искусного использования определенных ресурсов языка с целью скрытого влияния на когнитивную и поведенческую деятельность адресата» [6, c. 24], на смену которому в современной медиалингвистике приходит понятие мультимодальной манипуляции как «интеракции, через которую достигается тенденциозно преднамеренное, заинтересованное, завуалированное влияние на действия субъекта, осуществляемое в ряде случаев также в интересах третьих лиц» [7, с. 87]. Любая дискурсивная стратегия, «реактивирующая предпочтительные для адресанта когнитивные модели» [5, р. 363], может трансформироваться в манипулятивную.
В этой связи рассмотрим соотношение убеждения и манипуляции в акте информирования. Убеждение отличается от манипуляции степенью открытости и очевидности цели для реципиента: оно осуществляется открыто, а манипуляция всегда имплицитна, реализуется в подтекстовой форме. «Убеждение оставляет за адресатом выбор: он может как принимать навязываемые ему идеи, так и отвергать их» [5, p. 361], что позволяет ему оставаться субъектом коммуникации. При манипуляции же адресат участвует во взаимодействии неосознанно, принимает манипуляцию за информирование, при этом сохраняется «иллюзия самостоятельности принятия решений и осуществления действий» $[6$, с. 11], либо адресат осознает, что является объектом манипулирования, «когда практически ничего нельзя изменить» [8, c. 112]. Если принять в качестве общей посылки умозаключения утверждение, что любая манипуляция является убеждением, ср. «манипуляция часто рассматривается как форма убеждения» [9, с. 206], то логично предположить, что дискурс с целью убеждения потенциально может трансформироваться в манипулятивный в процессе коммуникации.

\section{Базовые характеристики манипуляции}

Выделяется ряд базовых характеристик манипуляции. Прежде всего, это отношения субъекта и объекта, или манипулирующего и манипулируемого. Акторами манипуляции являются люди, имеющие доступ к каким-либо формам публичного дискурса: политики, журналисты, ученые, писатели, маркетологи, блогеры и другие специалисты по созданию медиаконтента в социальных сетях. Заметим, что сегодня особый манипулятивный потенциал имеют так называемые «лидеры мнений» и инфлюэнсеры ${ }^{1}$.

Объектом же манипулирования становятся представители определенной социальной группы. Примечательно, что манипуляция обращена не к конкретному человеку, а к социальным группам и нацелена на охват все большей аудитории. При этом для успешного достижения цели актор имеет четкое представление о целевой группе и выбирает манипулятивные стратегии в соответствии с этим знанием. Актор управляет отношением объекта к явлениям окружающего мира в нужном для него русле и достигает своей цели благодаря в том числе и самому объекту манипуляции.

В ходе манипулирования информация в той или иной мере намеренно искажается, наблюдается доминирование выражения мнений над передачей

${ }^{1}$ В цифровом маркетинге под инфлюэнсером (от англ. influence - влиять) понимается собирательный термин, объединяющий публичных людей, оказывающих влияние на формирование мнения определенной аудитории. 
фактов. Канал передачи такой информации зачастую мультимодален.

Представляется возможным условно разделить манипулятивные дискурсивные стратегии по степени искажения информации на стратегии фактологического манипулирования и стратегии идеологической поляризации.

Фактологическое манипулирование характеризуется намеренным сокрытием и искажением информации, введением ложной информации, затушевыванием нежелательной информации, изменением фокуса освещения события и реализуется через такие стратегии, как фейк, дезинформация и пропаганда. Заметим, что «термин «фейк» не применим к оценочному суждению. «Человек имеет право на любую, в том числе и ошибочную оценку, поэтому прямое выражение оценки должно оцениваться не как факт, а как мнение», - отмечает И. А. Стернин [10, с. 4].

Под «пропагандой» понимают современную «политико-риторическую деятельность, организуемую государством и используемую в целях управления поведением масс с помощью символического воздействия на эмоционально-оценочную сферу и картину мира массового адресата» [11, с. 72]. Пропаганда отличается высокой степенью информационной агрессии.

Однако следует отметить, что и фейки, и пропаганда во многом являются реакцией на спрос со стороны объекта манипулирования. Люди «предпочитают ту информацию, которая соответствует их политическим взглядам или их картине мира» [12, c. 247], что обусловлено склонностью к стереотипности мышления и неумением критически проанализировать ситуацию. Причину популярности и эффективности фейка как средства манипулирования также следует искать в стремлении рецепиента избежать когнитивного диссонанса. Если же медиадискурс перестанет апеллировать к стереотипному знанию, разделяемому всеми носителями соответствующей субкультуры, этот диссонанс неизбежно наступит.

Вторая манипулятивная стратегия - идеологическая поляризация - реализуется через создание когнитивных моделей, которые заставляют реципиента острее чувствовать свою принадлежность к «своим» и отторгать «чужих». Целями поляризации являются позитивная презентация «Себя / Нас» и негативная «Другого / Их», педалирующие идеологическую принадлежность и идеологический конфликт.

Достижение эффекта в обоих случаях происходит за счет реализации макростратегий легитимации и дискредитации.

С связи с тем, что в чистом виде данные макростратегии встречаются редко, а чаще комбинируются в одном высказывании, можно говорить об их общих инструментах воздействия, а именно: использование морального превосходства и кредита доверия; обращение к ценностям, авторитетам и фонду общих знаний; гиперболизация, метафоризация и сравнения; сгущение негативных смыслов; использование эмоциональных аргументов вместо рациональных; эвфемизация и дисфемизация.

В таблице представлены выявленные отечественными исследователями основные стратегии и тактики манипулятивного воздействия.

\section{Макростратегия дискредитации}

Рассмотрим, как достигается манипулятивный эффект на примере отдельных тактических решений, связанных с дискредитацией актором своего оппонента.

Тактика обвинения состоит в создании негативного образа оппонента исключительно за счет лексики или конструкций с отрицательной коннотацией.

(1) The former first minister said that Ms Sturgeon had mislead parliament and broken the ministerial code with breaches including failing to inform the civil service in good time of her meetings with him (The Guardian).

Алекс Салмонд - лидер Шотландской национальной партии до 2014 г. - обвиняет свою последовательницу Н. Стержен - первого министра Шотландии (пример 1). При помощи таких средств, как mislead parliament (ввести в заблуждение членов парламенma), break the code, fail to inform (нарушить код, намеренно не проинформировать), создается негативный образ Н. Стержен как человека, не выполняющего свои обязательства и грубо нарушающего принятые нормы. Заметим, что критика не распространяется на политические решения Н. Стержен (так как она является преемницей Салмонда и лидером возглавляемой им ранее партии), а направлена на ее нравственные и деловые качества, представляющие, по мнению автора обвинения, угрозу устойчивости работы парламента. Фактологическая база в заявлении Салмонда отсутствует.

Тактика обличения с целью уличения оппонента состоит в приведении аргументов, делающих его виновность доказанной, - статистических данных и цитат из речей самого оппонента. Так, например, в дебатах с Д. Трампом Джо Байден подкрепляет свое заявление о виновности президента Трампа в смерти людей (responsible for many deaths) официальной статистикой смертности от коронавируса в США (пример 2). Обвиняя же его в несоблюдении эпидемиологических мер (he's been totally irresponsible, he's a fool on this), он апеллирует к словам самого Трампа о том, что его встречи с избирателями посетили сотни людей. Таким образом, обвинения Байдена («He's been totally irresponsible», "who's responsible for that many deaths», "He's a fool on this», "He's not worried about the people»), опираются на объективную инфор- 
Основные стратегии и тактики манипулятивного воздействия

\begin{tabular}{|c|c|c|c|}
\hline \multicolumn{2}{|c|}{ Макростратегия дискредитации } & \multicolumn{2}{|c|}{ Макростратегия легитимации } \\
\hline стратегии & тактики & стратегии & тактики \\
\hline \multirow{7}{*}{$\begin{array}{l}\text { Стратегия на пони- } \\
\text { жение [13], стратегия } \\
\text { дискредитации [14] }\end{array}$} & Анализ-минус & \multirow{7}{*}{$\begin{array}{l}\text { Стратегия на повыше- } \\
\text { ние [13] }\end{array}$} & Тактика анализ-«плюс» \\
\hline & Тактики обвинения, оскорбления & & $\begin{array}{l}\text { Тактики презентации и } \\
\text { неявной самопрезентации }\end{array}$ \\
\hline & Тактика безличного обвинения & & Тактика отвода критики \\
\hline & Тактика обличения & & \multirow[t]{4}{*}{ Тактика самооправдания } \\
\hline & Тактика угрозы & & \\
\hline & Тактика предположения [14] & & \\
\hline & $\begin{array}{l}\text { Тактика обращения к } \\
\text { авторитетному лицу или } \\
\text { фундаментальным ценностям [14] }\end{array}$ & & \\
\hline \multirow{3}{*}{$\begin{array}{l}\text { Стратегия } \\
\text { психологического } \\
\text { напряжения [14] }\end{array}$} & $\begin{array}{l}\text { Тактика «создания образа } \\
\text { тяжелого прошлого» }\end{array}$ & \multirow{3}{*}{$\begin{array}{l}\text { Стратегия } \\
\text { антидискредитации } \\
{[14]}\end{array}$} & Тактика опровержения \\
\hline & $\begin{array}{l}\text { Тактики «образа врага» и } \\
\text { «наклеивания ярлыка» }\end{array}$ & & \multirow[t]{2}{*}{$\begin{array}{l}\text { Тактика передачи защитного } \\
\text { слова авторитетному лицу }\end{array}$} \\
\hline & Тактика намека & & \\
\hline \multirow[t]{2}{*}{$\begin{array}{l}\text { Стратегия введения в } \\
\text { заблуждение [8] }\end{array}$} & Тактика ухода от определенности & \multirow[t]{2}{*}{$\begin{array}{l}\text { Стратегия } \\
\text { глорификации [14] }\end{array}$} & \multirow{2}{*}{$\begin{array}{l}\text { Тактики создания «образа } \\
\text { защитника» и «старшего } \\
\text { брата» }\end{array}$} \\
\hline & Тактика вопроса & & \\
\hline
\end{tabular}

мацию - данные статистики и свидетельства самого оппонента.

(2) Biden blames Trump for 200,000 US coronavirus deaths in explosive presidential debate. "Anyone who's responsible for that many deaths should not remain president of the United States of America, " he said. While Mr Trump boasted that thousands of people have attended his political rallies in recent months, Mr Biden said that was a black mark on the president's record, putting people's lives at risk. "He's been totally irresponsible the way in which he's handled the social distancing and people wearing masks, basically encouraging them not to. He's a fool on this. He's not worried about the people, " Mr Biden said (The Independent).

Во время президентских дебатов 2016 г. Х. Клинтон обличает Д. Трампа, выдвигая в качестве аргумента цитату из его речи, доказывающую его причастность к возникновению ипотечного кризиса. Она обращается как к статистическим данным (девять миллионов человек потеряли работу, пять миллионов человек потеряли жилье, семьи потеряли доходы на сумму в 13 триллионов долларов), так и апеллирует к цитате Трампа 2006 г. (пример 3).

(3) In fact, Donald was one of the people who rooted for the housing crisis. He said, back in 2006, "Gee, Ihope it does collapse, because then I can go in and buy some and make some money". Well, it did collapse. Nine million people - nine million people lost their jobs. Five million people lost their homes. And \$13 trillion in family wealth was wiped out (The New York Times).

Тактика оскорбления предполагает бездоказательное нанесение обиды, сопровождаемое экспликацией эмоционально-оценочного компонента. Проведение исторических, литературных или социальных параллелей между образом оппонента и образом, наделенным резко отрицательными ассоциациями, в определенном сообществе сближает эту тактику с тактикой создания «образа врага».

Так, в обращении Б. Джонсона к британской нации он позволил себе смоделировать наслаждение (дословно упоение), которое получит В. Путин от чемпионата мира по футболу 2018 г., по образу поведения А. Гитлера во время проведения Олимпийских игр в Берлине в 1936 г. (пример 4).

(4) Boris Johnson has predicted Vladimir Putin will revel in the World Cup in Russia this summer in the same way that Adolf Hitler did in the Olympic Games in Berlin in 1936, and suggested the UK may advise English football fans to avoid travelling to the tournament for their own safety (The Guardian).

Характерно, что оскорбительное сравнение с Гитлером вполне вписывается в общую картину де- 
монизации политического лидера России. Однако согласно статистике, для приехавших в Москву на чемпионат мира фанатов из Великобритании такая тактика не имела ожидаемого манипулятивного эффекта.

Еще одна тактика - угрозы - заключается в нагнетании страха, создании эффекта неотвратимости негативных последствий. Так, в своем сообщении в Твиттере Д. Трамп не просто заявляет об угрозе препятствия правосудию в случае прихода Байдена к власти, но и создает максимальный эффект трагедии при помощи лексической редупликации killers kill it all c эффектом необратимости происходящего (пример 5). Обвиняя оппонентов в шпионаже и государственной измене (spying, treason \& more), говорящий также культивирует страх у объектов своего манипулирования в случае прихода к власти Д. Байдена.

(5) IF Biden gets in, nothing will happen to Hunter or Joe. Barr will do nothing, and the new group of partisan killers coming in will quickly kill it all. Same thing with Durham. We caught them cold, spying, treason \& more (the hard part), but “Justice” took too long (Tweeter).

Тактикой с долгосрочным манипулятивным эффектом является тактика «наклеивания ярлька» (пример 6). 17 марта 2021 г. президент США в интервью телеканалу АВС утвердительно ответил на вопрос журналиста, считает ли он В. Путина убийцей killer.

(6) In the interview, when asked whether he thought Mr. Putin was a "killer," Mr. Biden responded: "Mmm hmm, I do." He further pledged that Mr. Putin is "going to pay" for Russian interference in the 2020 election (The New York Times).

Как видим, и журналист, и президент Байден, игнорируя дипломатические способы оценки действий оппонента, предпочитают тактику наклеивания оскорбительного ярлыка «убийцы» на В. Путина.

Все вышеприведенные тактики рассчитаны на дискредитацию оппонентов говорящего. Однако максимальное манипулятивное воздействие на аудиторию достигается не отдельными тактическими решениями, а комбинированием нескольких тактик и стратегий в одном высказывании, что создает «трехмерный» эффект и приводит к еще большей идеологической поляризации и усилению дихотомии «свой чужой». Нередко разные стратегии реализуются через одни и те же языковые средства.

\section{Макростратегия легитимации}

Данная макростратегия помогает оправдать в глазах аудитории правильность решения актора, добиться общественного признания своего поведения, получить разрешение на выполнение неких социальных действий. Пропозициональное содержание легитимации можно описать как «я имею право дей- ствовать таким образом в силу действия следующих факторов а, б, с» [15], что подразумевает право актора на подчинение реципиента.

Для изучения легитимации профессор Лодзинского университета П. Цап предлагает теорию проксимизации, обобщающую результаты многолетнего изучения политического дискурса США периода 2001-2010 гг. [16; 17]. Разработанная П. Цапом методика описания манипулятивного воздействия представляет собой «пропущенное звено... между критическим дискурс-анализом и когнитивной прагматикой» [16].

Изначально предназначенная для анализа легитимации «дискурса войны с терроризмом», данная методика успешно применяется в сфере цифровых технологий, экологии, здравоохранения, миграционной политики, политики безопасности, формирования национальной памяти.

Термин «проксимизация» от глагола proximize (буквально «приближать концептуально») является относительно новым в лингвистике. Проксимизация представляет собой манипулятивную стратегию обращения к событиям, отдаленным от текущего момента в пространственном, временно́м или аксиологическом плане, но способным перемещаться на первый план (усилиями актора), ближе к информационному центру, в котором находятся манипулятор и адресат.

Временна́я проксимизация создает конструкт концептуально связанных событий и соответствующих последствий, позволяющий приблизить давние, но значимые события в прошлом (за счет обращения к народной памяти) к текущему моменту, с целью создания напряженной атмосферы нарастающей угрозы с последующим запросом на незамедлительное принятие ответных мер. Так начинается опубликованная в декабре 2020 г. Морская стратегия США (пример 7).

(7) Our security and prosperity depend on the seas. Since the end of World War II, the United States has built, led, and advanced a rules-based international system... Free and open access to the world's oceans has fostered an extraordinary era of wealth and peace for many nations. That system is now at risk. Advantage at Sea is a Tri-Service Maritime Strategy that focuses on China and Russia, the two most significant threats to this era of global peace and prosperity (USNI News).

Временна́я проксимизация проявляется посредством приближения Актором тяжелых времен Второй мировой войны к центру «здесь и сейчас» для американской культуры - эре глобального мира и благоденствия (era of global peace and prosperity, an extraordinary era of wealth and peace), основанной на американском мировом господстве (где все на международной арене играют по правилам США - $a$ 
rules-based international system, и менять правила для всех может только США - the USA built, led, and advanced the system). Манипулируемый должен осознать, что имеется риск вернуться во времена до эры благоденствия, если не принять меры (Tri-Service Maritime Strategy) по устранению угроз со стороны Китая и России.

Аксиологическое измерение отражает ценностные ориентиры, помещаемые в дискурсивное пространство в виде лексических маркеров. Необходимая для манипулятора оценка интерпретируемого события достигается путем выявления противоречия между ценностями адресата и «чужими» ценностями и последующей аксиологической проксимизации, акцентирующей потенциальную возможность для чужих «негативных», «антагонистичных» ценностей материализоваться и укрепиться на территории внутреннего центра объекта манипулирования.

Так, в примере 8 ценностью контролируемой США глобальной культуры является свободная и открытая (free and open) торговля, которой противопоставляется «чуждая» ценность - авторитаризм Китая (China's authoritarian interests).

(8) Until China chooses to act as a responsible stakeholder rather than brandish its power to further its authoritarian interests, it represents the most comprehensive threat to the United States, our allies, and all nations supporting a free and open system (USNI News).

Очевидно, реализация проксимизации способствует достижению манипулятивного эффекта - страха и уверенности объекта в необходимости немедленных действий по предотвращению угрозы, что позволяет добиться легитимации планируемых действий (в данном случае, реализации Морской стратегии).

Другим примером может служить высказывание Д. Трампа, сделанное в ходе его встречи с избирателями в Миннесоте (пример 9).

(9) We will not make the mistakes made in European countries that allow a violent ideology to take root in our country, on our shores. We're not going to allow it to happen. As you all know, to protect our citizens from those who would do harm to us I instituted a very controversial, very hard to get travel ban on some of the world's most dangerous countries (The Washington Post).

Как видим, европейские страны представлены как допустившие ошибки в своей миграционной политике (mistakes made in European countries), следование которым в США - «внутреннем» центре (in our country, on our shores) - создает угрозу появления на территории США идеологии насилия (violent ideolo$g y)$. Здесь мы наблюдаем пространственную проксимизацию - угроза физически движется из «наиболее опасных стран мира» (the world's most dangerous countries) на территорию США - и аксиологическую, подразумевающую угрозу принятия ошибочных решений, идеологическим источником которых являются европейские страны, и угрозу укоренения в США идеологии других культур. Манипулятивный эффект связан с принятием за благо превентивных мер, а именно запрета на въезд в США из «опасных» стран (travel ban).

Стратегия проксимизации способствует сужению символического пространства между объектами манипулирования и их ценностями, акцентирует оппозицию «свой - чужой», создает эффект нагнетания страха и формирования запроса адресата на принятие срочных действий по предотвращению угрозы. Характерная для политического дискурса данная стратегия постоянно расширяет зону своего охвата, находя отражение в разнообразных текстах медиапространства.

\section{Заключение}

Рассмотренные в рамках статьи манипулятивные стратегии представляют собой необходимую основу для качественного и количественного анализа современных средств манипулирования массовым сознанием с точки зрения их успешности. Реализация макростратегий дискредитации и легитимации, направленных на опорочивание оппонента и одновременное оправдание собственных действий, делает реализуемый в медиапространстве дискурс в высшей степени манипулятивным, где ожидаемым результатом становится создание атмосферы страха и тревоги. Тенденциозное усиление примитивного противостояния «свой-чужой», упрощающего восприятие действительности и навязывающего адресату ложно ориентированные оценки, способствует поляризации настроений и снижению критического мышления в обществе, что, в свою очередь, облегчает манипулирование массовым сознанием при проведении действий захватнического или репрессивного характера. Выявление факторов успешности манипулятивных стратегий в англоязычном тексте параллельно с созданием «словника и грамматики манипуляции» будет способствовать алгоритмизации поиска манипулятивного контента на англоязычном медиапространстве.

\section{ЛИТЕРАТУРА}

1. Агапова С. Г., Гущиина Л. В. Роль эвфемизмов в информационной войне // Известия ЮФУ. Филологические науки. 2015. № 2. С. 56-63.

2. Данилова А. А. Манипулирование словом в средствах массовой информации. М. : КДУ, 2009. 234 с.

3. Антонова А. В. Система средств речевой манипуляции в британском политическом дискурсе : реципиентоцентрический подход : автореф. дис. ... д-ра филол. наук. Самара, 2011. 45 с. 
4. Доценко Е. Л. Психология манипуляции : феномены, механизмы и защита. М. : Изд-во МГУ, 1997. 344 с.

5. Dijk van T. A. Discourse and manipulation // Discourse and Society. 2006. Vol. 17 (3). Pp. 359-383.

6. Копнина Г. А. Речевое манипулирование : учеб. пособие. 4-е изд., испр. М. : Флинта, 2012. 170 с.

7. Гришаева Л. И., Пастухов А. Г., Чернышова Т. В. Средства и способы создания аксиологического контекста в медиатексте // Медиатекст : стратегии, функции, стиль : коллективная монография. Орел : Орлов. гос. ин-т искусств и культуры, 2010. С. 80-100.

8. Имя собственное в медиапространстве : монография / Л. И. Гришаева [и др.]. Воронеж : Издательский дом ВГУ, 2019. С. 107-182.

9. Озюменко В. И. Медийный дискурс в ситуации информационной войны : от манипуляции - к агрессии // Вестник РУДН. Сер.: Лингвистика. 2017. № 1. С. 203 220 .

10. Стернин И. А., Шестернина А. М. Маркеры фейка в медиатекстах. Рабочие материалы. Воронеж, 2020.34 c.

11. Михальская A. К. Война слов : риторика и поэтика пропаганды // Лингвистика информационно-психологической войны : монография / А. А. Бернацкая [и др.]. Красноярск : Сиб. федер. ун-т, 2019. Кн. II. С. 56-79.

12. Ершов Ю. М. Феномен фейка в контексте коммуникационных практик // Вестник ТГУ. Филология. 2018. № 52. C. 245-256.

13. Михалёва О. Л. Политический дискурс : специфика манипулятивного воздействия. М. : ЛИБРОКОМ, 2009. $256 \mathrm{c}$.

14. Тагильцева Ю. Р. Стратегии и тактики информационно-психологической войны в контексте российско-британских отношений // Лингвистика информационно-психологической войны : монография / А. А. Бернацкая [и др.]. Красноярск : Сиб. федер. ун-т, 2019. Кн. II. C. 308-331.

15. Рядовая Н. С. Сопоставительный анализ аргументативных стратегий политического дискурса в кризисной ситуации (на материале речей президентов США и России) : автореф. дис. ... канд. филол. наук. М., 2013. $28 \mathrm{c}$.

16. Cap P. Applying cognitive pragmatics to Critical Discourse Studies : A proximization analysis of three public space discourses // Journal of Pragmatics. 2014. № 70 (24). Pp. 16-30.

17. Cap P. The Language of Fear. London : Palgrave Macmillan, 2017.

\section{ИСТОЧНИКИ}

1. Sturgeon: SNP will hold Scottish independence vote if it wins in May // The Guardian. 2021. 24 Jan. URL: https:// www.theguardian.com/politics /2021/jan/24/scotlandindependence-referendum-nicola-sturgeon-snp-wins-may

2. 'He panicked': Biden blames Trump for 200,000 US coronavirus deaths in explosive presidential debate // The Independent. 2020. 30 Sept. URL: https://www.independent. co.uk/news/world/americas/us-election/trump-bidendebate-coronavirus-deaths-mask-b706371.html

3. Transcript for the first debate // The New York Times. 2016. 28 Sept. URL:https://www.nytimes.com/2016/09/27/ us/politics/transcript-debate.html

4. Boris Johnson compares Russian World Cup to Hitler's 1936 Olympics // The Guardian. 2018. 21 March. URL: https://www.theguardian.com/football/2018/mar/21/ boris-johnson-compares-russian-world-cup-to-hitlers-1936olympics

5. Trump's Tweeter. 2020. 12 Dec. URL: https://www. facebook.com /DonaldTrump/posts/if-biden-gets-innothing-will-happen-to-hunter-or-joe-barr-will-do-nothingand-t/10165960000965725/

6. Russia Erupts in Fury Over Biden's Calling Putin a Killer // The New York Times. 2021. 18 March. URL: https:// www.nytimes.com/2021/03/18/world/europe/russia-bidenputin-killer.html

7. 'Stunning in ugliness \& tone': Trump denounced for attacking Somali refugees in Minnesota // The Washington Post. 2019. 11 Oct. URL: https://www.washingtonpost.com /nation/2019/10/11/trump-somali-refugees-minneapolisrally/

8. U.S. Maritime Strategy : Advantage at Sea // U.S. Naval Institute News. 2020. 17 December. URL: https:// news.usni.org/2020/12/17/u-s-maritime- strategyadvantage-at-sea

\section{REFERENCES}

1. Agapova S. G., Agapova E. A., Gushhina L. V. Manipulyativnye strategii i taktiki v politicheskom diskurse angloyazychnykh SMI: monografiya [Manipulative strategies and tacktics in political discourse of English-speaking mass media: monography]. Rostov-upon-Don, 2015. 93 p.

2. Danilova A. A. Manipulirovanie slovom v sredstvakh massovoj informatsii [Manipulation with a word in the mass media]. Moscow: «KDU», 2009. 234 p.

3. Antonova A. V. Sistema sredstv rechevoj manipulyatsii v britanskom politicheskom diskurse: retsipientotsentricheskij podkhod [The system of means of speech manipulation in the British political discourse: recipient-centred approach]. Sc.D Dissertation Abstract. Povolzh'e State Socio-humanitarian Academy: Samara, 2011. 45 p.

4. Dotsenko E. L. Psikhologiya manipulyatsii: fenomeny, mekhanizmy i zashhita [Psychology of manipulation: phenomena, mechanisms and protection]. Moscow: MGU, 1997. 344 p.

5. Dijk van T. A. Discourse and manipulation. In: Discourse and Society. 2006. Vol. 17 (3). Pp. 359-383.

6. Kopnina G. A. Rechevoe manipulirovanie: ucheb. posobie [Speech manipulation: textbook]. 4 izd. ispr. Moscow: Flinta: Nauka, 2012. 170 p.

7. Grishaeva L. I. Sredstva i sposoby sozdaniya aksiologicheskogo konteksta v mediatekste. In: Mediatekst: strategii funktsii stil': kollektivnaya monografiya [Means and methods of creating axiological context in a media text. In: Media text: strategies, functions, style: collective mono- 
grapthy]. L. I. Grishaeva, A. G. Pastukhov, T. V. Chernysheva (otv. red.). Oryol: Oryol State Institute of Arts and Culture, 2010. Pp. 80-100.

8. Funktsional'nyj potentsial imeni sobstvennogo $\mathrm{v}$ mediaprostranstve, ili «korolevstvo krivykh zerkal». In: Imya sobstvennoe v mediaprostranstve: monografiya. [Functional capacity of proper names or "Kingdom of crooked mirrors". In: Proper names on the media scene]. L. I. Grishaeva, O. O. Boriskina, N. A. Fenenko, V. N. Ababij, V. G. Shimko ; Voronezh State University. Voronezh: VGU, 2019. Pp. 107-182.

9. Oziumenko V. I. Medijnyj diskurs v situatsii informatsionnoj vojny: ot manipulyatsii - k agressii [Media discourse in a situation of information war: from manipulation to aggression]. In: Vestnik RUDN. Series: Linguistics. 2017. Issue 1. Pp. 203-220.

10. Sternin I. A., Shesternina A. M. Markery fejka v mediatekstakh. Rabochie materialy [Markers of a fake in media texts: Working materials]. Voronezh: OOO «RITM», 2020. 34 p.

11. Mikhal'skaya A. K. Vojna slov: ritorika i poehtika propagandy. In: Lingvistika informatsionno-psikhologicheskoj vojny: monografiya [War of words: rhetoric and poetics of propaganda. In: Linguistics of information and psychological war]. B. II / A. A. Bernatskaya, L. A. Gavrilov, V. A. ZHilina. Krasnoyarsk: Siberian Federal University, 2019. Pp. 56-79.

12. Ershov Yu. M. Fenomen fejka v kontekste kommunikatsionnykh praktik [Phenomenon of fake in the context of communication practices]. In: Vestnik TGU. Filologiya. 2018. Issue 52. Pp. 245-256.

13. Mikhalyova O. L. Politicheskij diskurs: Spetsifika manipulyativnogo vozdejstviya [Political discourse: Specificity of manipulative persuasion]. Moscow: LIBROKOM, 2009. $256 \mathrm{p}$.

14. Tagil'tseva Yu. R. Strategii i taktiki informatsionno-psikhologicheskoj vojny v kontekste rossijsko-britanskikh otnoshenij. In: Lingvistika informatsionno-psikhologicheskoj vojny: monografiya [ Strategies and tactics of information and psychological war in the context of Russia - UK relations. In: Linguistics of information and psychological war]. B. II / A. A. Bernatskaya, L. A. Gavrilov, V. A. ZHilina. Krasnoyarsk: Siberian Federal University, 2019. Pp. 308-331.

15. Ryadovaya N. S. Sopostavitel'nyj analiz argumentativnykh strategij politicheskogo diskursa v krizisnoj situatsii (na materiale rechej prezidentov SShA i Rossii) [Comparative analysis of argumentative strategies of political

Воронежский государственный университет

Недзельская А. Б., аспирант кафедры теоретической и прикладной лингвистики

E-mail:nedzelskaya@vsu.ru discourse in crisis situation (on the material of speeches by the USA and Russia's Presidents]. PhD Dissertation Abstract. Omsk State Pedagogical University: Moscow, 2013. $28 \mathrm{p}$.

16. Cap P. Applying cognitive pragmatics to Critical Discourse Studies: A proximization analysis of three public space discourses. In: Journal of Pragmatics. 2014. Issue 70 (24). Pp. 16-30.

17. Cap P. The Language of Fear. London: Palgrave Macmillan, 2017.

\section{SOURCES}

1. Sturgeon : SNP will hold Scottish independence vote if it wins in May. In: The Guardian. 2021. 24 Jan. Available at: https://www.theguardian.com/politics /2021/jan/24/ scotland-independence-referendum-nicola-sturgeon-snpwins-may

2. 'He panicked': Biden blames Trump for 200,000 US coronavirus deaths in explosive presidential debate. In: The Independent. 2020. 30 Sept. Available at: https://www. independent.co.uk/news/world/americas/us-election/trumpbiden-debate-coronavirus-deaths-mask-b706371.html

3. Transcript for the first debate. In: The New York Times. 2016. 28 Sept. Available at: https://www.nytimes. com/2016/09/27/us/politics/transcript-debate.html

4. Boris Johnson compares Russian World Cup to Hitler's 1936 Olympics. In: The Guardian. 2018. 21 March. Available at: https://www.theguardian.com/football/2018/ mar/21/boris-johnson-compares-russian-world-cup-tohitlers-1936-olympics

5. Trump's Tweeter. 2020. 12 Dec. Available at: https:// www.facebook.com /DonaldTrump/posts/if-biden-gets-innothing-will-happen-to-hunter-or-joe-barr-will-do-nothingand-t/10165960000965725/

6. Russia Erupts in Fury Over Biden's Calling Putin a Killer. In: The New York Times. 2021. 18 March. Available at: https://www.nytimes.com/2021/03/18/world /europe/ russia-biden-putin-killer.html

7. 'Stunning in ugliness \& tone': Trump denounced for attacking Somali refugees in Minnesota. In: The Washington Post. 2019. 11 Oct. Available at: https://www.washingtonpost.com /nation/2019/10/11/trump-somali-refugees-minneapolis-rally/

8. U.S. Maritime Strategy : Advantage at Sea. In: U.S. Naval Institute News. 2020. 17 December. Available at: https://news.usni.org/2020/12/17/u-s-maritime-strategyadvantage-at-sea

Voronezh State University

Nedzelskaya A. B., Post-graduate Student of the Theoretical and Applied Linguistics Department

E-mail: nedzelskaya@vsu.ru 
Борискина О. О., доктор филологических наук, профессор кафедры теоретической и прикладной лингвистики

E-mail: boriskinatipl@mail.ru

Поступила в редакцию 10 марта 2021 г.

Принята к публикации 22 марта 2021 г.

\section{Для цитирования:}

Недзельская А. Б., Борискина О. О. Манипулятивные стратегии в англоязычном медиапространстве // Вестник Воронежского государственного университета. Серия: Лингвистика и межкультурная коммуникация. 2021. № 2. C. 73-82. DOI: https://doi.org/10.17308/lic.2021.2/3417
Boriskina O. O., Doctor of Philology, Professor of the Theoretical and Applied Linguistics Department

E-mail: boriskinatipl@mail.ru

Received: 10 March 2021

Accepted: 22 March 2021

\section{For citation:}

Nedzelskaya A. B., Boriskina O. O. Manipulative strategies on English-language media scene. Proceedings of Voronezh State University. Series: Linguistics and Intercultural Communication. 2021. No. 2. Pp. 73-82. DOI: https:// doi.org/10.17308/lic.2021.2/3417 